\title{
Cyclic vomiting syndrome: diagnostic approach and current management strategies
}

This article was published in the following Dove Press journal: Clinical and Experimental Gastroenterology

\section{William J Hayes' \\ Deidra VanGilder ${ }^{2}$ \\ Joseph Berendse ${ }^{3}$ \\ Michael D Lemon ${ }^{3}$ \\ John A Kappes ${ }^{4}$}

'Department of Pharmacy Practice, South Dakota State University, Regional Health Medical Clinic, Rapid City, SD, USA; ${ }^{2}$ South Dakota State University, College of Pharmacy and Allied Health Professions, Brown Clinic, Watertown, SD, USA; ${ }^{3}$ Department of Pharmacy Practice, South Dakota State University, College of Pharmacy and Allied Health Professions, VA Black Hills Health Care System, Fort Meade, SD, USA; ${ }^{4}$ Department of Pharmacy Practice, South Dakota State University, College of Pharmacy and Allied Health Professions, Rapid City Regional Hospital, Rapid City, SD, USA
Correspondence: William J Hayes Department of Pharmacy Practice, South Dakota State University, College of Pharmacy and Allied Health Professions, Regional Health Medical Clinic, 640 Flormann Street, Rapid City-5770I, SD, USA

Tel + I 6057553407

Email william.hayes@sdstate.edu

\begin{abstract}
Cyclic vomiting syndrome (CVS) is a disorder characterized by episodes of nausea and vomiting lasting for 1-5 days followed by asymptomatic periods. The etiology of CVS is unknown, but it shares similar characteristics to migraine headaches. CVS is generally classified as having four phases: prodromal, acute/vomiting/hyperemesis, recovery, and remission/ interepisodic. Current management strategies include trigger avoidance, abortive and prophylactic medication therapies, and supportive care. The goal of therapy for the remission phase is prophylaxis of further episodes. Antidepressant, antiepileptic, and antimigraine medications show an overall reduction or remission of CVS symptoms in more than $70 \%$ of patients. This article provides a summary of diagnostic strategies and reviews current management strategies for CVS. Keywords: cyclic vomiting syndrome, emesis, hyperemesis, vomiting, CVS
\end{abstract}

\section{Introduction}

Cyclic vomiting syndrome (CVS) is a chronic disorder characterized by sudden episodes of nausea and vomiting lasting for 1-5 days followed by asymptomatic periods..$^{1-6}$ The incidence of CVS is unknown in adult patients but is said to occur in 3\%-14\% of adults referred for unexplained nausea and vomiting. ${ }^{1}$ The frequency is cited as $0.04 \%-2 \%$ for pediatric patient populations. ${ }^{3-5}$ CVS is more prevalent in Caucasians and slightly more in males. The average initial diagnosis age in pediatric and adult populations is 5.2 and 25.4 years of age, respectively. ${ }^{4}$ Diagnosis is often delayed with a mean of 15 emergency department (ED) visits prior to identification. Patients are often perceived to demonstrate drug seeking behavior. ${ }^{7} \mathrm{CVS}$ is associated with menses (catamenial CVS), migraine headaches, diabetes mellitus, or precipitated by pregnancy. ${ }^{1}$

Symptoms of CVS in adult populations are characterized by emesis and diffusely radiated epigastric abdominal pain. ${ }^{1,2,5} \mathrm{CVS}$ is generally regarded as having four phases: prodromal/pre-emetic, acute (also known as vomiting and hyperemesis), recovery, and remission/interepisodic. ${ }^{1,5,8}$ Some patients describe an aura during the prodromal phase lasting for several minutes or up to hours, usually consisting of abdominal pain, anorexia, lethargy, pallor, or autonomic symptoms such as sweating or salivation. ${ }^{4}$ Emotional stress, energy-depleting states (eg, lack of sleep, fasting, and infection), certain food products (eg, chocolate, cheese, and monosodium glutamate), and menstrual cycles may trigger the acute phase. ${ }^{1,4}$ The acute phase usually starts in the early morning or mid-day and consists of intense persistent nausea with repeated vomiting up to eight times every hour. ${ }^{4,8,9}$ The average duration of acute phase symptoms is 3.4 days in pediatrics and 5.9 days in adults. Patients typically seek medical attention 
during the acute phase. Endoscopic findings can include peptic esophagitis and hemorrhagic lesions of the gastric mucosa as a result of the vomiting episodes. ${ }^{5}$ During the recovery phase, vomiting stops, energy levels increase, and appetite returns. ${ }^{4}$ Following the recovery phase, the patient enters a symptom-free phase considered remission. Annual average frequency of CVS is 9.6 and 14.4 episodes per year in pediatric and adult populations, respectively. Still, a wide range of annual frequencies are observed in these patient populations.

Various hypotheses of CVS pathogenesis are cited in the literature. Proposed mechanisms for CVS include psychological or physical stress resulting in activation of the hypothalamic-pituitary-adrenal axis, ${ }^{10}$ abnormal gastric emptying (eg, irritable bowel syndrome) ${ }^{11}$ dysfunction in the autonomic nervous system, ${ }^{12}$ mitochondrial dysfunction, ${ }^{13}$ elevated levels of ghrelin, ${ }^{14}$ and food allergies. ${ }^{5}$ Other conditions with an observed association with CVS include gastroesophageal reflux syndrome (GERD), psychiatric disorders (eg, anxiety and depression), chronic marijuana use, and diabetes mellitus. ${ }^{3,15}$ Studies show a close association of CVS and migraine headaches, especially in pediatric patients. ${ }^{1-5}$ The prevalence of headaches or migraine headaches is $36.5 \%$ in adult CVS patients. ${ }^{4}$ Furthermore, prevalence of a family history of migraines is $56 \%$ in adult CVS patients. Though not fully understood, this association suggests a common pathophysiological mechanism with a diverse array of symptoms caused by a more generalized underlying central nervous system disorder. ${ }^{16}$ This hypothesis describes CVS as a variant of migraine in which headache may not be present, but may have an aura prior to acute phase.

This article summarizes the diagnostic approach and reviews current medication management strategies for CVS.

\section{Diagnosis}

The diagnostic criteria for adult CVS according to the Rome IV criteria are stereotypic episodes of vomiting with the following characteristics: at least two acute-onset episodes in the past 6 months, each occurring at least 1 week apart, and persisting for less than 1 week. ${ }^{1}$ Furthermore, there is an absence of vomiting between episodes, but other milder symptoms can occur between cycles. Supportive findings include a personal or family history of migraine. Conversely, the International Headache Society guidelines for CVS are similar but recommend a minimum of five attacks of intense nausea and vomiting in any interval for the diagnosis of $\mathrm{CVS}^{2}$ The Rome IV workgroup cites five studies using two attacks in the past 6 months with adequate specificity to diagnosis. The workgroup states early diagnosis is important and therefore retained the minimum number of two episodes in the past 6 months to diagnose CVS. In addition, the word "nausea" was left out as the Rome IV workgroup stating that this symptom is difficult to assess in infants due to the inability to communicate its presence.

Contrary to previous guidelines, Rome IV divided patients with prolonged excessive cannabis use from CVS into a novel condition known as cannabinoid hyperemesis syndrome (CHS). ${ }^{1}$ Moreover, Rome IV describes Chronic nausea vomiting syndrome which differs from CVS by distinct temporal characteristics of weekly acute episodes. Several rare conditions mimic the presentation of CVS, including acute intermittent porphyria (which also has associated neurologic symptoms) and disorders of fatty acid oxidation.

The Rome IV workgroup recommends a more extensive diagnostic workup in patient presenting with bilious vomiting, abdominal tenderness, abnormal neurologic findings, or a worsening pattern of vomiting episodes. Biochemical testing to dismiss hypothyroidism, hypercalcemia, Addison's disease, and other electrolyte and acid-base abnormalities are prudent. Drug screening is also considered to see if CHS is a possibility. Upper endoscopy, small bowel radiography, computed tomography, or magnetic resonance enterography can assess for gastroduodenal disease and small bowel obstruction. Computed tomography of the head may rule out space-occupying lesions. If these tests are unremarkable, consider obtaining a gastric-emptying evaluation. The Rome IV workgroup states if severe symptoms persist, antroduodenal or normal manometry can assess for enteric neuropathy or myopathy. Esophageal $\mathrm{pH}$ testing may dismiss vomiting as an atypical presentation of GERD. Furthermore, consideration of urine measurements of aminolevulinic acid and porphobilinogen, plasma ammonia levels, plasma amino acid, and urine organic acid quantification may exclude some rare conditions.

\section{Treatment}

Treatment goals in CVS are to identify and avoid triggering factors, prevent recurrent acute episodes with prophylactic medication therapy, ameliorate acute episodes with abortive treatment and supportive care, and provide psychological support to the patient and family. ${ }^{1,3}$ Though several classes of medications are utilized for long-term management of CVS, remission of symptoms is not achievable in every patient. The main risk factors for nonresponse include coexisting poorly controlled migraine headaches, psychiatric disorders, and chronic opioid or marijuana use. ${ }^{17}$ In addition, medications 
used for CVS prophylaxis carry the potential for undesirable adverse effects or complications. Table 1 provides the summary of literature regarding CVS treatment.

\section{Acute phase}

Acute phase treatment goals of CVS symptoms include preventing dehydration and terminating nausea, vomiting, and abdominal pain. ${ }^{3}$ Dextrose, saline, and potassium replacement is used for hydration. ${ }^{1,6}$ Abortive intravenous antiemetic agents, especially $5-\mathrm{HT}_{3}$ (serotonin type 3 ) receptor antagonists (eg, ondansetron), are generally effective. Other antiemetic agents such as promethazine and diphenhydramine are also considered effective. ${ }^{3}$ Benzodiazepines (eg, lorazepam 1-2 mg intravenously every 3 hours) can be considered for admitted patients requiring deep sedation or sleep induction. Intravenous opioids or ketorolac may be initially warranted to treat severe abdominal pain in the acute setting. Antimigraine serotonin 5-HT ${ }_{1 \mathrm{~B}, 1 \mathrm{D}}$ agonists (eg, sumatriptan) have provided anecdotal success in children with personal or family histories of migraines, and therefore, can also be considered in adults with the presence of such histories.

\section{Remission phase}

The goal of therapy for remission phase is prophylaxis of further episodes. ${ }^{5}$ Antidepressant, antiepileptic, and antimigraine pharmacotherapies show an overall reduction or remission of CVS symptoms in more than $70 \%$ of patients. ${ }^{4}$

\section{Tricyclic antidepressants}

Tricyclic antidepressants (TCAs), including amitriptyline, nortriptyline, and doxepin have been studied for the prophylaxis of $\mathrm{CVS}^{18-22}$ and are considered a first line treatment for prophylaxis of CVS by reducing the frequency and severity of attacks in children and adults. ${ }^{4}$ However, adverse effects of TCAs may limit their use in patients under the age of 5 years. Mechanistically, TCAs increase synaptic concentrations of norepinephrine and serotonin in the central nervous system, but their efficacy in CVS could be related to anticholinergic and alpha-2 adrenergic modulation. ${ }^{17}$ Starting doses of TCAs typically range from 10 to $25 \mathrm{mg}$ /day given at night with patients adjusting to the drowsiness over 2-3 months. Doses of TCAs are typically increased in increments every $2-3$ weeks. Studies commonly used a dosing goal of 1 $\mathrm{mg} / \mathrm{kg} /$ day. Adverse effects noted in the trials include sedation, behavior changes (in young children), arrhythmia, and anticholinergic effects. ${ }^{6,17}$ Using nortriptyline is an option to decrease anticholinergic adverse effects. Due to arrhythmia and the prolongation of the QT interval, consider a baseline electrocardiogram in TCA patients. While TCAs are considered first line for prophylaxis, the supporting data comes from small studies which measured a variety of different outcomes.

Efficacy of TCAs was demonstrated in 27 adult patients (average age of 29 years, range 19-62) diagnosed using Rome II criteria who received amitriptyline for at least 3 months. ${ }^{18}$ The patients receiving amitriptyline started at $25-50 \mathrm{mg}$ and titrated with a target dose of $1 \mathrm{mg} / \mathrm{kg} /$ day over the next 1-2 months. The dose was decreased if the patient experienced adverse effects. Efficacy was based on a 2-point decrease in a visual analog pain scale. Decreased symptoms based on the visual analog pain scale were demonstrated in $93 \%$ of patients and $26 \%$ of patients achieved full remission of CVS symptoms. Study authors also concluded that higher dosing of the amitriptyline was important in improving patient symptoms over time.

Efficacy of several TCAs was shown in an open label study of 41 adult patients who received amitriptyline (38 patients), nortriptyline (two patients), or doxepin (one patient) with up to 2 years of follow-up. ${ }^{19}$ Patients met the Rome III criteria for CVS and questionnaires/interviews were completed at baseline and at 6 month intervals assessing the number of episodes of CVS, number of ED visits, number of hospitalizations, and duration of CVS episodes before and after starting TCA therapy. TCA therapy was started at doses ranging from 10 to $25 \mathrm{mg}$ once daily and titrated to effect. Other supportive medications allowed during the study included lorazepam for anxiety, antiemetics for nausea, antimigraine treatment, anticholinergics for abdominal pain, and over the counter medications L-carnitine and coenzyme Q10. Overall, 93\% of patients showed decreased frequency and severity of symptoms. Full remission was achieved by $26 \%$ of patients. Significant improvement was seen in the frequency of CVS episodes per year decreasing from 17.8 at baseline to 5.4 after the first year and to 3.3 after the second year of TCA therapy ( $p=0.003$ and $p=0.002$, respectively). The duration of CVS episodes in days decreased significantly from 6.7 to 2.5 after the first year and 2.2 after second year ( $p=0.0009$ and $p=0.0008$, respectively). Also, the number of ED visits and hospitalizations per year decreased significantly from 15 at baseline to 4.2 at first year and 3.3 at second year ( $p=0.009$ and $p=0.007$, respectively). A goal dose of $1 \mathrm{mg} /$ $\mathrm{kg} /$ day for TCA therapy was used, and an average dose of 100 $\mathrm{mg}$ /day was achieved with a range of $15-200 \mathrm{mg} /$ day $(0.25-3$ $\mathrm{mg} / \mathrm{kg} /$ day) in the study. Mild medication-related adverse effects occurred in 34\% of patients, but no one discontinued TCA therapy. Of the patients experiencing adverse effects, $12 \%$ experienced dry mouth, $9 \%$ somnolence, $7 \%$ chronic 
Table I Summary of evidence for CVS treatment

\begin{tabular}{|c|c|c|}
\hline Treatment & Citation & Medication and doses \\
\hline \multicolumn{3}{|l|}{ Abortive treatment } \\
\hline IV hydration with dextrose and & Stanghellini et al' & $10 \%$ dextrose with $0.45 \%-0.9 \%$ normal saline ${ }^{1,6}$ \\
\hline potassium & Li et $\mathrm{al}^{6}$ & \\
\hline 5-HT3 receptor antagonists & Stanghellini et al' & Ondansetron \\
\hline (eg, ondansetron) & Li et $\mathrm{al}^{6}$ & Doses not provided \\
\hline \multirow[t]{2}{*}{ Antiemetic } & Hejazi et $\mathrm{al}^{3}$ & Promethazine or diphenhydramine \\
\hline & & Doses not provided \\
\hline Benzodiazepines & Hejazi et $\mathrm{al}^{3}$ & Lorazepam intravenous $\mathrm{I}-2 \mathrm{mg}$ every 3 hours \\
\hline IV opioids & Hejazi et $\mathrm{al}^{3}$ & $N / A$ \\
\hline IV ketorolac & Hejazi et $\mathrm{al}^{3}$ & $\mathrm{~N} / \mathrm{A}$ \\
\hline \multirow{4}{*}{$5-\mathrm{HT}_{\mathrm{IB}, \mathrm{ID}}$ agonist } & Hejazi et $\mathrm{al}^{3}$ & Sumatriptan \\
\hline & Hikita et $\mathrm{al}^{29}$ & $6 \mathrm{mg}$ subcutaneous injection (adult), or \\
\hline & & 20 mg nasal spray, or \\
\hline & & Age-based dosing $[(\text { age } \times 4+20) / 100 \times 3 \mathrm{mg}]^{29}$ \\
\hline \multirow[t]{4}{*}{ NKI receptor antagonists } & Cristofori et $\mathrm{al}^{33}$ & Aprepitant \\
\hline & & $125 \mathrm{mg}$ orally initially, followed if required by $80 \mathrm{mg}$ on day 2 and 3 in children $>20 \mathrm{~kg}, 80$ \\
\hline & & $\mathrm{mg}$ for 3 consecutive days for those weighing between 15 and $20 \mathrm{~kg}$, at $80 \mathrm{mg}$ at day I and \\
\hline & & $40 \mathrm{mg}$ on day 2 and 3 for those children $<15 \mathrm{~kg}$ \\
\hline \multicolumn{3}{|l|}{ Prophylaxis treatment } \\
\hline \multirow[t]{12}{*}{ Tricyclic antidepressants } & Li et $\mathrm{al}^{6}$ & Amitriptyline (children $>5$ years old) \\
\hline & Namin et al $^{18}$ & Starting dose: $0.25-0.5 \mathrm{mg} / \mathrm{kg}$ per day at bedtime (titrate weekly by $5-10 \mathrm{mg}$ ) \\
\hline & Hejazi et al ${ }^{19}$ & Target dose: $\mathrm{I}-\mathrm{I} .5 \mathrm{mg} / \mathrm{kg}$ per day at bedtime \\
\hline & Hejazi et $a^{20}$ & Amitriptyline (adult) ${ }^{18,19,22}$ \\
\hline & Kumar et $\mathrm{al}^{21}$ & Starting dose: $10-50 \mathrm{mg}$ daily \\
\hline & Haghighat et $\mathrm{al}^{22}$ & Target dose: I mg/kg/day or titrated to effect \\
\hline & & Nortriptyline (adult) $)^{19}$ \\
\hline & & Starting dose: $10-25 \mathrm{mg}$ daily \\
\hline & & Target dose: titrated to effect \\
\hline & & Doxepin (adult) ${ }^{19}$ \\
\hline & & Starting dose: $10-25 \mathrm{mg}$ daily \\
\hline & & Target dose: titrated to effect \\
\hline \multirow[t]{16}{*}{ Antiepileptic } & Sezer et $\mathrm{al}^{23}$ & Topiramate (pediatric) ${ }^{23}$ \\
\hline & Hikita et $\mathrm{al}^{26}$ & Starting dose: 25 mg daily \\
\hline & Gokhale et $\mathrm{al}^{27}$ & Effective dose range: $25-75 \mathrm{mg} /$ day \\
\hline & Clouse et $\mathrm{al}^{28}$ & Valproate (pediatric) ${ }^{26}$ \\
\hline & & Starting dose: 10 mg/kg/day (in 2 divided doses) \\
\hline & & Effective dose range: $20-40 \mathrm{mg} / \mathrm{kg} /$ day \\
\hline & & Phenobarbital (pediatric) ${ }^{27}$ \\
\hline & & Starting dose: $\sim 2$ mg/kg/day (median: 60 mg) \\
\hline & & Effective dose range: $30-120 \mathrm{mg} /$ day \\
\hline & & Zonisamide (adult) $)^{28}$ \\
\hline & & Starting dose: 100 mg daily \\
\hline & & Effective dose range: $100-700 \mathrm{mg} /$ day \\
\hline & & (median: $400 \mathrm{mg}$ ) \\
\hline & & Levetiracetam (adult) ${ }^{28}$ \\
\hline & & Starting dose: 500 mg daily \\
\hline & & Effective dose range: $500-3000$ mg/day (median: 1000 mg) \\
\hline \multirow[t]{3}{*}{ Antimigraine } & Haghighat et $\mathrm{al}^{22}$ & Propranol \\
\hline & Sezer et $\mathrm{al}^{23}$ & Starting dose: 1 mg/kg/day ${ }^{23,30}$ \\
\hline & Haghighat et $\mathrm{al}^{30}$ & Target dose: titrated to effect ${ }^{23}$ \\
\hline \multirow{2}{*}{ Histamine $\mathrm{H}_{1}$ antagonist } & Badihian et $\mathrm{al}^{31}$ & Cyproheptadine \\
\hline & & Various doses used \\
\hline \multirow[t]{3}{*}{ NKI receptor antagonists } & Cristofori et $\mathrm{al}^{33}$ & Aprepitant \\
\hline & & $40 \mathrm{mg}$ orally twice/week in children $<40 \mathrm{~kg}, 80 \mathrm{mg}$ in children $40-60 \mathrm{~kg}$, and $125 \mathrm{mg}$ in \\
\hline & & children $>60 \mathrm{~kg}$ \\
\hline \multirow[t]{4}{*}{ Dietary supplement } & Kumar et $\mathrm{al}^{21}$ & I-carnitine ${ }^{2 I}$ \\
\hline & Boles et $\mathrm{al}^{34}$ & I g twice daily \\
\hline & & Coenzyme Q $\mathbf{I O}^{21}$ \\
\hline & & 200 mg twice daily \\
\hline
\end{tabular}

Abbreviations: CVS, cyclic vomiting syndrome; IV, intravenous; 5-HT, serotonin; NKI, neurokinin-I. 
fatigue, and $2 \%$ constipation, blurred vision, and mild hallucinations. While two-thirds of patients continued with the same dose, dose reduction of the TCA was used to manage adverse effects in the other patients.

Hejazi et al conducted a prospective, open label trial in 132 adults to identify TCA nonresponders. ${ }^{20}$ Mean length of follow-up was 1.6 years with a range of $1.2-4.3$ years. In the study, 101 patients considered responders received amitriptyline, ten patients received nortriptyline, and four patients received doxepin. Nonresponders included 16 patients on amitriptyline, and one on nortriptyline. The frequency of CVS episodes per year decreased from 17.6 at baseline to 5.5 in the TCA response group after 1 year compared to 21.3 at baseline to 21.8 after 1 year in the TCA nonresponders. Duration of CVS episodes decreased from 6.6 to 2.8 days in the responders versus 5.8 to 5.2 days in the TCA nonresponders. The number of hospitalizations and ED visits per year decreased in the TCA responders from 15.2 to 4.1 while they stayed similar in the TCA nonresponders at 18 to 18.3 after 1 year of therapy. The mean TCA dose in TCA responders was $85 \mathrm{mg}$ per day (10-250) and $90 \mathrm{mg}$ per day (25-250) in TCA nonresponders, thereby eliminating inadequate dose as a reason for treatment nonresponse. Significant differences between the responders and nonresponders included chronic marijuana use (22\% vs 53\%, respectively), chronic narcotic use $(15 \%$ vs $53 \%)$, history of migraine headaches $(20 \%$ vs $41 \%)$, and coexisting depression or anxiety disorders $(10 \%$ vs $35 \%$ ).

Tricyclic antidepressants efficacy was also assessed in a retrospective review of 101 CVS patients diagnosed using the Rome III criteria. ${ }^{21}$ Authors concluded that response to standard CVS prophylactic therapy was similar between adult and pediatric patients. Tricyclic antidepressants were used in 70 patients and included amitriptyline and nortriptyline. The mean TCA dose was $83.3 \mathrm{mg}$ with a range of 46-120 mg per day. Of the 70 patients on TCAs, 18 patients had to discontinue therapy due to bad dreams, behavioral changes, and increased somnolence. Efficacy of the TCAs was demonstrated in 44 patients $(58 \%)$ with a complete response and 21 patients $(28 \%)$ with a partial response. There were 11 patients $(14 \%)$ with no response to therapy.

Nonresponders had a higher incidence of chronic opioid use $(46 \%$ vs. $13 \% p=0.02)$ and were less compliant with treatment ( $38 \%$ vs $88 \% p=0.004)$

Finally, a prospective study with 181 children with CVS compared amitriptyline to propranolol over a 11 -year period to determine response to prophylactic therapy. ${ }^{22}$ Both amitriptyline and propranolol were dosed at $1 \mathrm{mg} / \mathrm{kg} /$ day. The mean age at diagnosis was 6.9 years with a range $1.5-14$ years. Both medications demonstrated a significant response with $56 \%$ $(46 / 81)$ of patients in the amitriptyline group $(p<0.001)$ and $92 \%(74 / 83)$ of patients in the propranolol group $(p<0.0001)$. A potential limitation when interpreting this data is that response was not defined. Adverse effects in the amitriptyline group included irritability, insomnia, lethargy, or agitation.

\section{Antiepileptic}

Topiramate has been studied for prophylactic treatment of CVS, primarily via case reports and small retrospective studies among pediatric patients. ${ }^{21,23,24} \mathrm{~A}$ recent retrospective study comparing topiramate to propranolol among 38 pediatric CVS patients found topiramate superior in reducing the frequency of acute attacks. ${ }^{23}$ Patients were initiated on either topiramate $25 \mathrm{mg}$ or propranolol $1 \mathrm{mg} / \mathrm{kg} /$ day and titrated to effect. After 12 months of treatment, $81 \%$ of patients on topiramate compared to $59 \%$ of patients on propranolol were free from attacks $(p=0.05)$. Additionally, topiramate had a significantly lower nonresponse rate than propranolol (defined as $<50 \%$ reduction from baseline in number of acute attacks; $6 \%$ vs $18 \% ; p=0.001$ ). Adverse effects reported by those in the topiramate arm included drowsiness and dizziness, without significant difference between groups ( $p=0.15)$. Patients were monitored for weight change from baseline and no significant difference was found.

Valproate and phenobarbital are two additional antiepileptics with limited data for prophylactic treatment of CVS in pediatric populations. ${ }^{25-27}$ In a recent prospective trial in Japan, 18 hospitalized pediatric patients with severe CVS underwent prophylactic treatment with one of the ten regimens. ${ }^{25}$ Regimens included various antiepileptics, amitriptyline, cyproheptadine, propranolol, and clonidine. Patients failing to respond to one therapy could subsequently trial another. Patients were deemed responsive to therapy if they experienced less than two acute phase attacks per year; at baseline, patients had attacks every 8 weeks, on average. Of the ten different regimens, only valproate (nine of 15 patients), phenobarbital (three of nine patients), amitriptyline (one of five patients), and combination therapy of phenobarbital with valproate (four of four patients) were associated with treatment response. Other antiepileptic regimens not associated with treatment response included carbamazepine, primidone, and phenytoin. Incidence of adverse effects was not reported.

Other antiepileptic medications are used as salvage treatment for CVS. Zonisamide and levetiracetam have limited data from a small retrospective study investigating their role in prophylaxis for adult CVS patients. ${ }^{28}$ Twenty patients who 
had failed or did not tolerate TCA prophylaxis were started on either zonisamide ( $\mathrm{n}=16$; median dose of $400 \mathrm{mg} /$ day after titration) or levetiracetam $(\mathrm{n}=4$; median dose of $1000 \mathrm{mg}$ / day after titration). Chart review revealed after initiation of antiepileptic therapy, there was a significant decrease in the frequency of vomiting episodes (1.3-0.5 episodes/month; $p=0.01)$. There was a non-significant trend toward moderate or greater improvement in symptoms per patient self-report ( $75 \%$ for each group, $p=0.8$ ). Twenty percent of patients in either treatment reported severe adverse effects including fatigue, confusion, headache, and dizziness. Only one patient was intolerant to treatment with either antiepileptic.

\section{Antimigraine}

Sumatriptan is a proven abortive treatment option for CVS. In a small study of 12 patients (11 children and 1 adult), vomiting was reduced in $75 \%$ of patients treated with either injectable or intranasal sumatriptan. ${ }^{29}$ Response to treatment was classified as complete resolution of symptoms (no vomiting after treatment), effective (frequency of vomiting reduced by at least half) or noneffective. In total, 35 attacks were treated with injectable sumatriptan and 19 attacks $(54 \%)$ were classified as responsive to treatment. Six attacks were treated with intranasal sumatriptan and two had effective resolution of symptoms. Greater efficacy was seen in patients with a family history of migraines in a first-degree relative ( $p=0.0482$ ). No adverse effects were associated with sumatriptan treatment in this study. Other case reports with successfully administration of sumatriptan in the treatment of CVS have also been published.

Previous studies with propranolol have proven it should be considered as a prophylactic option to control symptoms and prevent attacks. ${ }^{22,23}$ It is most commonly used in pediatrics and has shown moderate response rates in several studies which included a large number of patients compared to other available treatments. A 2015 study of 301 children with similar baseline characteristics and an average age of 5.98 years, evaluated the addition of a one week, daily oral dose of erythromycin $20 \mathrm{mg} / \mathrm{kg} /$ day to 9 months of daily propranolol $1 \mathrm{mg} / \mathrm{kg} /$ day oral treatment. ${ }^{30}$ Response was defined as a 1 month symptom free period after completion of therapy. Recurrence was described as return of symptoms after 6 months symptom free. Both groups showed significant response rates with the combination regimen having a significant increase in response rate $(77.39 \%-90.32 \% ; p=0.002)$. Similar recurrence and relapse rates were seen with no significant differences.
Badihian et al conducted a single-blinded randomized clinical trial to evaluate the efficacy of amitriptyline and cyproheptadine as prophylactic treatment. ${ }^{31}$ The 6 month study included 64 children aged 3-15 years with similar baseline characteristics who were equally randomized to treatment. During the last 2 months of the study, the frequency of CVS attacks was $0.38 \pm 0.55$ and $0.59 \pm 71$ in the amitriptyline and cyproheptadine groups $(p=0.197)$. The mean duration of attacks was $1.41 \pm 2.86$ hours and $1.81 \pm 2.22$ hours in the same groups. Complete remission, classified as $100 \%$ recovery, was seen in 21 patients $(65.6 \%)$ receiving amitriptyline and 16 patients $(50 \%)$ with cyproheptadine respectively. Adverse effects, including increased appetite and restlessness were seen in two patients receiving cyproheptadine compared to three patients with amitriptyline. No patients discontinued because of adverse effects. Cyproheptadine has been used successfully as a prophylactic treatment option in pediatric patients. The studies had a limited number of patients but promising response rates. ${ }^{32}$

\section{Refractory patients}

Second-line approaches to CVS treatment typically target specific comorbid symptoms or conditions. Agents include benzodiazepines (eg, lorazepam) in anxiety disorders, antispasmodics (eg, dicyclomine) for irritable bowel syndrome-like abdominal pain, proton pump inhibitors for esophagitis secondary to repeated vomiting, antiemetic agents (eg, ondansetron, promethazine, or prochlorperazine) for refractory nausea, and analgesics (eg, tramadol, ketorolac, and infrequently limited opioids) for abdominal pain management. ${ }^{2}$

A novel approach to treating CVS is the use of neurokinin (NK1) receptor antagonists. Aprepitant was the first NK1 receptor antagonist approved for prevention of chemotherapy induced nausea and vomiting. Aprepitant appears to also have antidepressant and anxiolytic effects. A recent trial in 41 pediatric patients, refractory to conventional CVS therapies were treated acutely or prophylactically with aprepitant. ${ }^{32}$ The prophylactic dose of aprepitant $40 \mathrm{mg}$ orally twice/ week in children $<40 \mathrm{~kg}, 80 \mathrm{mg}$ in children $40-60 \mathrm{~kg}$, and $125 \mathrm{mg}$ in children $>60 \mathrm{~kg}$. An acute regimen of aprepitant was given at $125 \mathrm{mg}$ orally at the beginning of prodromal phase at least 30 minutes before the acute phase when all the patients were able to swallow the capsule, followed if required by $80 \mathrm{mg}$ on day 2 and 3 in children $>20 \mathrm{~kg}, 80$ $\mathrm{mg}$ for 3 consecutive days for those weighing between 15 and $20 \mathrm{~kg}$, at $80 \mathrm{mg}$ at day, 1 and $40 \mathrm{mg}$ on day 2 and 3 for 
those children $<15 \mathrm{~kg}$. At 12 months on intention-to-treat analysis, 13 children (81\%) taking aprepitant prophylactically achieved either complete $(3 / 16,19 \%)$ or partial $(10 / 16$, $62 \%$ ) clinical response. Of those taking aprepitant acutely, 19 children $(76 \%)$ had either complete $(3 / 25,12 \%)$ or partial $(16 / 25,64 \%)$. Adverse effects included hiccups (19\%), fatigue $(12.5 \%)$, increased appetite $(12.5 \%)$, mild headache $(6 \%)$, and severe migraine $(6 \%)$.

Other second-line therapies for nonresponders include medications that improve mitochondrial function (eg, L-carnitine or coenzyme Q10). Coenzyme Q10 and L-carnitine use is based on the hypothesis that CVS is result of mitochondrial dysfunction which leads to an energy imbalance.

Coenzyme Q10 was found to be effective in 68\% of CVS patients. ${ }^{34}$ Several case series have found L-carnitine effective. ${ }^{35,36}$

Other therapies demonstrating successful CVS treatment in case reports and case series include chlorpromazine, ${ }^{37}$ gonadotropin releasing hormone analogue, ${ }^{38}$ mirtazapine,${ }^{39}$ onabotulinumtoxin $\mathrm{A},{ }^{40}$ and risperidone. ${ }^{41}$

\section{Conclusion}

CVS is an uncommon diagnosis with an unknown etiology and pathophysiology. Acute symptoms of CVS are debilitating and usually require medical attention. Treatment goals in CVS include identification and avoidance of triggering factors. Prophylactic therapies exist and demonstrate benefit in the literature, despite moderate adverse effects. Antidepressant, antiepileptic, and antimigraine medications show an overall reduction or remission of CVS symptoms in more than $70 \%$ of patients. Future research should explore the etiology, pathophysiology, and pharmacotherapy of CVS.

\section{Disclosure}

The authors report no conflicts of interest in this work.

\section{References}

1. Stanghellini V, Chan FK, Hasler WL, et al. Gastroduodenal disorders. Gastroenterology. 2016;150(6):1380-1392.

2. The International Classification of Headache Disorders, $3^{\text {rd }}$ ed. Headache Classification Committee of the International Headache Society (IHS). Cephalalgia. 2013;33(9):629-808.

3. Hejazi RA, McCallum RW. Review article: cyclic vomiting syndrome in adults - rediscovering and redefining an old entity. Aliment Pharmacol Ther. 2011;34(3):263-273.

4. Lee LY, Abbott L, Mahlangu B, Moodie SJ, Anderson S. The management of cyclic vomiting syndrome: a systematic review. Eur J Gastroenterol Hepatol. 2012;24(9):1001-1006.

5. Pareek N, Fleisher DR, Abell T. Cyclic vomiting syndrome: what a gastroenterologist needs to know. Am J Gastroenterol. 2007;102(12): 2832-2840.
6. Li BU, Lefevre F, Chelimsky GG, et al. North American Society for pediatric gastroenterology, hepatology, and nutrition consensus statement on the diagnosis and management of cyclic vomiting syndrome. J Pediatr Gastroenterol Nutr. 2008;47(3):379-393.

7. Venkatesan T, Tarbell S, Adams K, et al. A survey of emergency department use in patients with cyclic vomiting syndrome. BMC Emerg Med. 2010;10:4.

8. Fleisher DR, Gornowicz B, Adams K, Burch R, Feldman EJ. Cyclic vomiting syndrome in 41 adults: the illness, the patients, and problems of management. BMC Med. 2005;3:20.

9. Levinthal DJ, Bielefeldt $K$. Adult cyclical vomiting syndrome: a disorder of allostatic regulation? Exp Brain Res. 2014;232(8):2541-2547.

10. Taché Y. Cyclic vomiting syndrome: the corticotropin releasing factor hypothesis. Dig Dis Sci. 1999;44(8 Suppl):79S-86S.

11. Hejazi RA, Lavenbarg TH, McCallum RW. Spectrum of gastric emptying patterns in adult patients with cyclic vomiting syndrome. Neurogastroenterol Motil. 2010;22(12):1298-1302.

12. Venkatesan T, Prieto T, Barboi A, et al. Autonomic nerve function in adults with cyclic vomiting syndrome: a prospective study. Neurogastroenterol Motil. 2010;22(12):1303-1307.

13. Wang Q, Ito M, Adams K, et al. Mitochondrial DNA control region sequence variation in migraine headache and cyclic vomiting syndrome. Am J Med Genet A. 2004;131(1):50-58.

14. Hejazi RA, Lavenbarg T, McCallum RW. Elevated serum ghrelin level in adults with cyclic vomiting syndrome. Am J Gastroenterol. 2011;106(10):1858-1859.

15. Bashashati M, McCallum RW. Neurochemical mechanisms and pharmacologic strategies in managing nausea and vomiting related to cyclic vomiting syndrome and other gastrointestinal disorders. Eur $J$ Pharmacol. 2014;722:79-94.

16. Levinthal DJ. The cyclic vomiting syndrome threshold: a framework for understanding pathogenesis and predicting successful treatments. Clin Transl Gastroenterol. 2016;7(10):e198.

17. Hejazi RA, McCallum RW. Cyclic vomiting syndrome: treatment options. Exp Brain Res. 2014;232(8):2549-2552.

18. Namin F, Patel J, Lin Z, et al. Clinical, psychiatric, and manometric profile of cyclic vomiting syndrome in adults and response to tricyclic therapy. Neurogastroenterol Motil. 2007;19(3):196-202.

19. Hejazi RA, Reddymasu SC, Namin F, Lavenbarg T, Foran P, McCallum RW. Efficacy of tricyclic antidepressant therapy in adults with cyclic vomiting syndrome: a two-year follow-up study. J Clin Gastroenterol. 2010;44(1):18-21.

20. Hejazi RA, Lavenbarg TH, Foran P, McCallum RW. Who are the nonresponders to standard treatment with tricyclic antidepressant agents for cyclic vomiting syndrome in adults? Aliment Pharmacol Ther. 2010;31(2):295-301.

21. Kumar N, Bashar Q, Reddy N, et al. Cyclic vomiting syndrome (CVS): is there a difference based on onset of symptoms-pediatric versus adult? BMC Gastroenterol. 2012;12:52.

22. Haghighat M, Rafie SM, Dehghani SM, Fallahi GH, Nejabat M. Cyclic vomiting syndrome in children: experience with 181 cases from southern Iran. World J Gastroenterol. 2007;13(12):1833-1836.

23. Sezer OB, Sezer T. A new approach to the prophylaxis of cyclic vomiting: topiramate. J Neurogastroenterol Motil. 2016;22(4):656-660.

24. Olmez A, Kose G, Turanli G. Cyclic vomiting with generalized epileptiform discharges responsive to topiramate therapy. Pediatr Neurol. 2006;35(5):348-351.

25. Hikita T, Kodama H, Ogita K, Kaneko S, Nakamoto N, Mimaki M. Cyclic vomiting syndrome in infants and children: a clinical follow-up study. Pediatr Neurol. 2016;57:29-33.

26. Hikita T, Kodama H, Nakamoto N, et al. Effective prophylactic therapy for cyclic vomiting syndrome in children using valproate. Brain Dev. 2009;31(6):411-413.

27. Gokhale R, Huttenlocher PR, Brady L, Kirschner BS. Use of barbiturates in the treatment of cyclic vomiting during childhood. $J$ Pediatr Gastroenterol Nutr. 1997;25(1):64-67. 
28. Clouse RE, Sayuk GS, Lustman PJ, Prakash C. Zonisamide or levetiracetam for adults with cyclic vomiting syndrome: a case series. Clin Gastroenterol Hepatol. 2007;5(1):44-48.

29. Hikita T, Kodama H, Kaneko S, et al. Sumatriptan as a treatment for cyclic vomiting syndrome: a clinical trial. Cephalalgia. 2011;31(4): 504-507.

30. Haghighat M, Dehghani SM, Shahramian I, Imanieh MH, Teimouri A, Noori NM. Combination of erythromycin and propranolol for treatment of childhood cyclic vomiting syndrome: a novel regimen. Gastroenterol Hepatol Bed Bench 2015;8(4):270-277.

31. Badihian N, Saneian H, Badihian S, Yaghini O. Prophylactic therapy of cyclic vomiting syndrome in children: comparison of amitriptyline and cyproheptadine: a randomized clinical trial. Am J Gastroenterol. 2018;113(1):135-140.

32. Madani S, Cortes O, Thomas R. Cyproheptadine use in children with functional gastrointestinal disorders. J Pediatr Gastroenterol Nutr. 2016;62(3):409-413.

33. Cristofori F, Thapar N, Saliakellis E, et al. Efficacy of the neurokinin-1 receptor antagonist aprepitant in children with cyclical vomiting syndrome. Aliment Pharmacol Ther. 2014;40(3):309-317.

34. Boles RG, Lovett-Barr MR, Li BU, Adams K. Treatment of cyclic vomiting syndrome with coenzyme Q10 and amitriptyline, a retrospective study. BMC Neurol. 2010;10:10.
35. Van Calcar SC, Harding CO, Wolff JA. L-carnitine administration reduces number of episodes in cyclic vomiting syndrome. Clin Pediatr (Phila). 2002;41(3):171-174.

36. Boles RG. High degree of efficacy in the treatment of cyclic vomiting syndrome with combined co-enzyme Q10, L-carnitine and amitriptyline, a case series. BMC Neurol. 2011;11:102.

37. Ozdemir HH, Bulut S, Berilgen MS, Kapan O, Balduz M, Demir CF. Resistant cyclic vomiting syndrome successfully responding to chlorpromazine. Acta Medica (Hradec Kralove). 2014;57(1): 28-29.

38. Shin YK, Kwon JG, Kim KY, et al. A case of cyclic vomiting syndrome responding to gonadotropin-releasing hormone analogue. J Neurogastroenterol Motil. 2010;16(1):77-82.

39. Bae SM, Kang SG, Lee YJ, Cho SJ, Seo CM. Rapid response to mirtazapine in cyclic vomiting syndrome refractory to conventional prokinetics. Psychosomatics. 2014;55(3):311-312.

40. Hayes WJ, Weisensee LA, Kappes JA, Dalton SM, Lemon MD. OnabotulinumtoxinA injections for the treatment of cyclic vomiting syndrome. Pharmacotherapy. 2015;35(5):e51-55.

41. Hermus IP, Willems SJ, Bogman AC, Janssen PK, Brabers L, Schieveld JN. Cyclic vomiting syndrome: an update illustrated by a case report. Prim Care Companion CNS Disord. 2016;18(3).
Clinical and Experimental Gastroenterology

\section{Publish your work in this journal}

Clinical and Experimental Gastroenterology is an international, peerreviewed, open access, online journal publishing original research, reports, editorials, reviews and commentaries on all aspects of gastroenterology in the clinic and laboratory. This journal is included on PubMed. The manuscript management system is completely online

\section{Dovepress}

and includes a very quick and fair peer-review system, which is all easy to use. Visit http://www.dovepress.com/testimonials.php to read real quotes from published authors. 